\title{
Uso de ferramentas da bioinformática para determinação dos possíveis efeitos do $\beta$-caroteno no cultivo in vitro de Phalaenopsis
}

Fernanda Kelly Mezzalira, Betty Cristiane Kuhn

Universidade Tecnológica Federal do Paraná - UTFPR, Campus Dois Vizinhos, PR. E-mail: fernanda_mezzalira25@hotmail.com, bettykuhn@utfpr.edu.br

\section{Resumo}

Ornamentais demonstram interesse econômico, dentre elas o maior número de comercializações resulta de orquídeas do gênero Phalaenopsis. O cultivo in vitro tem como objetivo propagar um número elevado de plantas com qualidade fitossanitárias. A bioinformática, auxilia na busca por genomas semelhantes de organismos, cujas informações genéticas estejam armazenadas em bancos de dados. O objetivo do trabalho foi determinar os efeitos do $\beta$-caroteno no desenvolvimento da Phalaenopsis cultivada in vitro, e determinar o meio de cultura adequado para germinação e desenvolvimento da Phalaenopsis, analisando o gene e a proteína do $\beta$-caroteno da Daucus carota. Foram testados três tratamentos para germinação de sementes de Phalaenopsis híbrida, um meio de cultura Knudson, meio de cultura Murashige e Skoog (MS) e o meio de cultura Knudson com incremento de $10 \%$ (v/v) de suco de cenoura. Seguido de um teste para o cultivo das plântulas de Phalaenopsis híbrida em quatro tratamentos, o meio de cultura Knudson, o meio Murashige e Skoog, meio Knudson com incremento de reguladores de crescimento (BAP/ANA) e o meio Knudson suplementado com suco de cenoura em $10 \%(\mathrm{v} / \mathrm{v})$. Os resultados demonstram que o suco de cenoura é benéfico para a germinação e desenvolvimento de orquídeas do gênero Phalaenopsis. Através da análise de bioinformática com uso do CLUSTAL e do BLAST, obteve-se informações sobre o gene e a proteína do $\beta$-caroteno da Daucus carota e verificou-se que, um substituto para a cenoura na elaboração dos meios de cultura é a Citrus sinensis. A Citrus sinensis é uma fonte abundante de ácido cítrico, que auxilia na redução de oxidação em plantas cultivadas in vitro. Conclui-se que o meio adequado para o cultivo de Phalaenopsis híbrida é o meio suplementado com suco de cenoura e que, possivelmente é o $\beta$ caroteno presente na cenoura, o responsável pelos benefícios no desenvolvimento das plântulas.

Palavras-Chave: biotecnologia; Daucus carota; micropropagação; orquídeas.

Use of bioinformatics tools for determination of possible effects of $\beta$-carotene in in vitro Phalaenopsis cultivation

\begin{abstract}
Ornamental plants show economic interest, among the greatest number of commercializations results from orchids of the genus Phalaenopsis. In vitro cultivation aims to propagate a high number of plants with phytosanitary quality. Bioinformatics, helps in the search for similar genomes of organisms, whose genetic information is stored in database. The objective of the work was to determine the effects of $\beta$-carotene on the development of Phalaenopsis grown in vitro, and to determine the appropriate culture médium for germination and development of Phalaenopsis, analyzing the gene and protein of Daucus carota $\beta$ carotene. Three treatments for germination of hybrid Phalaenopsis seeds were tested, a Knudson culture médium, Murashige and Skoog (MS) and Knudson with a $10 \%(\mathrm{v} / \mathrm{v})$ incremente of carrot juice. Followed by test for the cultivation of hybrid Phalaenopsis seedlings in four treatments, the Knudson culture médium, MS, Knudson whit increased growth regulators (BAP/ANA) and Knudson médium supplemented with carrot juice $10 \%(\mathrm{v} / \mathrm{v})$. The results demonstrate that carrot juice is beneficial for the germination and development of orchids of the genus Phalaenopsis. Through bioinformatics analysis using CLUSTAL and BLAST, information was obtained on the Daucus carota $\beta$-carotene gene and protein and it was found that a substitute for carrots in the preparation of culture médium is Citrus sinensis. Citrus sinensis is na abundant source of citric acid, which helps to reduce oxidation in plants grown in vitro. It is concluded that the
\end{abstract}


médium suitable for the cultivation of Phalaenopsis is the médium supplemented whith carrot juice and that it is possibly the $\beta$-carotene presente in the carrot, which is responsible for the benefits in the seedling development.

Keywords: biotechnology; Daucus carota; micropropagation; orchids.

\section{Introdução}

A família Orchidaceae possui aproximadamente 35.000 espécies distribuídas no planeta, excluindo regiões desérticas e polares (BARROS et al., 2018). Dentre as ornamentais, as orquídeas, contribuem expressivamente com o PIB (Produto Interno Bruto) brasileiro, o boletim informativo do Instituto Brasileiro de Floricultura (Ibraflor) estima-se que o mercado internacional de plantas ornamentais movimente mais de US\$ 70 bilhões anuais (SCHOENMAKER, 2017; COSTA, 2013).

O mercado florícolo é movimentado pela comercialização de plantas destinadas a harmonização de ambientes internos, em um ranking realizado pela Royal Flora Holland, a orquídea Phalaenopsis ocupa a primeira colocação de vendas com aproximadamente 139 milhões de unidades (ROYAL FLORA HOLLAND, 2018).

A Phalaenopsis tem origem no sudeste asiático, com preferência por temperaturas entre 18 e 28 oC, é uma orquídea monopodial, alternifólias, com inflorescência nas axilas foliares e acaba sempre em meristema vegetativo (MINAMIGUCHI; MACHADO NETO, 2007). A produção da Phalaenopsis é elevada em países como o Japão, Alemanha, China, Holanda e Tailândia. Segundo Schoenmaker (2017) na Holanda, uma das maiores importadoras de plantas ornamentais, tem-se comercializado aproximadamente 2,3 milhões de Phalaenopsis em uma semana.

Naturalmente, a propagação de orquídeas ocorre por dissipação de sementes ou brotações (HOFFMANN, 1997), entretanto somente 3-5 \% das sementes conseguem germinar (TOMBOLATO; COSTA, 1998), pois, as sementes precisam se manter em contato com fungos do tipo micorriza, presentes em raízes de plantas adultas da mesma espécie sendo um processo extremamente lento, além da exposição recorrente da planta a ação de pragas e doenças (HOFFMANN, 1997).

A micropropagação, método da cultura de tecidos vegetais in vitro, é amplamente empregada em plantas ornamentais. Tem como objetivo obter um número elevado de plantas, em tempo de cultivo reduzido quando comparada com a propagação natural, mantendo plantas com qualidades fitossanitárias. Um dos fatores que influência, a eficácia do procedimento, é o meio de cultura. Geralmente o meio usado para o cultivo de orquídeas deve ser rico em vitaminas, sais minerais, e água (ZAHARA et al., 2017). Na literatura encontram-se uma gama de aditivos orgânicos utilizados, dentre eles destacam-se a água de coco, extrato de banana, extrato de batata e suco de tomate em razão destes aditivos auxiliarem nas etapas de germinação, micropropagação e crescimento das plantas (ZAHARA et al., 2016; GNASEKARAN et al., 2010; MURDAD et al., 2010).

Dentre os meios de culturas já estabelecidos, são mais utilizados para cultivo in vitro de espécies vegetais o meio de Knudson (1964), Vacin e Went (1949) e Murashige e Skoog (1962). Entretanto, quanto ao arranjo nutricional que beneficia a germinação e crescimento de orquídeas in vitro, o discernimento é muito carente (JORGE et al., 2015).

Não há na literatura, um meio de cultura especifico para cada gênero, clone, híbrido ou espécie de orquídea. Há uma complexidade no relato do por que certas associações de componentes do meio de cultura apresentem resultados satisfatórios e outros não apresentam tal êxito (MIYATA et al., 2014). Entretanto Zahara (2017) afirma que o meio de cultivo Knudson suplementado com suco de cenoura obteve ótimos resultados para o cultivo da Phalaenopsis híbrida pink, a cenoura apresenta pigmentação laranja devido aos carotenoides, que auxiliam na etapa vital para sobrevivência das plantas que é a fotossíntese (KRINSKY, 1994; NAVES, 1998).

Para obter informações sobre os dados de gene e proteína de um componente, como o $\beta$-caroteno que é o principal carotenoide da cenoura, pode-se fazer uso de ferramentas da bioinformática. Essa ferramenta auxilia no estudo mais detalhado, sobre o genoma dos organismos e seus possíveis efeitos. Conforme citado por 
Prosdocimi e Santos (2004) “a bioinformática tem como base a análise computacional de sequências de DNA, RNA e proteínas". Essa ciência analisa de modo sofisticado dados oriundos da biologia molecular (ALVES, 2013). $\mathrm{Na}$ biotecnologia, a bioinformática age na compreensão de proteínas, suas funções e interações, no estudos de patógenos e resistências de plantas, entre demais aplicações (LOPES, 2012).

Diante da problemática apresentada o objetivo principal do projeto é determinar os efeitos do $\beta$-caroteno no desenvolvimento de orquídeas do gênero Phalaenopsis cultivadas in vitro, e os objetivos específicos referem-se a determinar o meio de cultura adequado para o desenvolvimento da Phalaenopsis, assim como possíveis modificações de componentes. Visando a redução do tempo de cultivo e a viabilidade econômica.

\section{Metodologia}

Experimento 1: Determinação do meio de cultura para germinação de sementes de Phalaenopsis. A assepsia foi realizada com dupla lavagem em solução de hipoclorito de sódio $20 \%$, concentração previamente estabelecida e eficaz na assepsia para sementes de orquídeas, a primeira lavagem por 3 minutos e a segunda lavagem por 5 minutos. Posteriormente, foram realizadas seis lavagens com água destilada autoclavada, cerca de $1 \mathrm{~mL}$ de água com sementes foram inoculados nos frascos contendo meio de cultura.

Os tratamentos realizados nesse experimento são disponibilizados na tabela 1.

Tabela 1. Tratamentos utilizados para o experimento 1

\begin{tabular}{cc}
\hline $\begin{array}{c}\text { Experimento } 1 \\
\text { Tratamentos }\end{array}$ & Composição \\
\hline T1 & Meio Knusdon (1964) \\
T2 & Meio MS (1949) \\
& Meio Knudson $+10 \%(\mathrm{v} / \mathrm{v})$ Suco de \\
T3 & Cenoura \\
\hline
\end{tabular}

Fonte: Autor (2019).

Os tratamentos consistiram no uso do meio Knudson (KNUDSON, 1946) e do meio MS (MURASHIGE; SKOOG 1962) adquirido comercialmente (SIGMA-ALDRICH, 2019a), conforme consta na literatura. $\mathrm{O}$ meio de cultura suplementado com aditivo orgânico, trata-se de

um meio Knudson com $10 \%(\mathrm{v} / \mathrm{v}$ ) de suco de cenoura processada in natura como realizado no trabalho de Zahara et al. (2017).

Foram realizadas quatro repetições para cada um dos três tratamentos estabelecidos, logo o delineamento é um fatorial $4 \times 3$, obtendo-se 12 frascos. Os frascos foram mantidos em sala de cultivo com temperatura de 24-25 으, fotoperíodo de 8 horas escuro e 16 horas claro. Após 60 dias, o parâmetro analisado ao fim do experimento foi o tamanho das plântulas germinadas (em $\mathrm{mm}$ ). Foram utilizados frascos de vidro padronizados de $260 \mathrm{~mL}$, contendo $60 \mathrm{~mL}$ de meio de cultura.

A análise estatística consistiu na medição, com papel milimetrado, do tamanho de 10 plântulas de cada tratamento. A partir, dos resultados aplicou-se teste de separação de Tukey a 5\% de significância utilizando a ferramenta excel. Observou-se a significância dos resultados, para o presente trabalho.

Experimento 2: Determinação do meio de cultura adequado para o cultivo in vitro de Phalaenopsis híbrida. Neste experimento foram testados quatro tratamentos (tabela 2), o meio Knudson não foi utilizado nesta etapa, em função dos resultados obtidos no experimento 1 , uma vez que foi o meio de cultura com resultados insatisfatórios.

Tabela 2. Tratamentos utilizados para o experimento 2

\section{Experimento 2}

Tratamentos Composição

T1

$\mathrm{T} 2$

T3

$\mathrm{T} 4$

*O T4 teve incremento de BAP: 0,04 mg/L; e ANA: 0,02 $\mathrm{mg} / \mathrm{L}$

Fonte: Autor (2019)

Os tratamentos do presente experimento consistiram nos meios de cultura MS (MURASHIGE; SKOOG 1962), com a concentração normal, MS (MURASHIGE; SKOOG 1962), com o dobro de sua concentração normal, Knudson (KNUDSON, 1946) suplementado com $10 \%$ (v/v) de suco de cenoura (ZAHARA et al., 2017), e o último tratamento consistiu no meio Knudson (KNUDSON, 1946) suplementado com 
reguladores de crescimento, realizando uma combinação de auxina e citocinina, o mais indicado segundo a literatura, de BAP $(6$ benzilaminopurina) e ANA (ácido naftalenoacético) nas seguintes concentrações: BAP 0,04 mg/L e ANA 0,02 mg/L (FOGAÇA, 2010).

As repetições consistiram em 8 frascos para cada tratamento, cada frasco contendo 5 plantas, logo o delineamento foi casualizado em um fatorial de $8 \times 4 \times 5$. Os frascos foram mantidos em sala de cultivo com temperatura de 24-25 으, fotoperíodo de 8 horas escuro e 16 horas claro por 365 dias. Foram utilizados frascos de vidro padronizados de $260 \mathrm{~mL}$, contendo $60 \mathrm{~mL}$ de meio de cultura.

Os parâmetros foram analisados após 120 dias e 365 dias, analisando: Número de Calos (Ca); Número de Brotos (Br); Altura da parte Aérea do maior Broto (APA); Número de Raízes do maior Broto (NR); Comprimento da Raiz mais Longa do maior Broto (CRL); Peso Médio Úmido (PM); Porcentagem de Perecimento (\% Per); Porcentagem de Oxidação (\% Oxi).

A análise estatística utilizada nos experimentos foi um teste de Tukey com 95\% de significância, utilizando excel. As medições foram realizadas com papel milimetrado. Observou-se a significância dos resultados para o presente trabalho.
Experimento 3: $O \quad \beta$-caroteno, principal componente da cenoura foi analisado por meio de pesquisa em bancos de dados online (NCBI, EMBL-EBI, UniProt).

A sequência do gene e da proteína do $\beta$-caroteno da Daucus carrot foi obtida no NCBI. Alinhamentos foram realizados entre as sequencias de interesse, com organismos cujas, informações genéticas estavam armazenadas em bancos de dados, por meio da ferramenta BLAST (AMARAL, 2007) (Basic Local Alignment Search Tool), do NCBI, a qual utilizou-se o BLASTX, para alinhamento entre nucleotídeo traduzido e proteína, e o PROTEIN BLAST para alinhamento proteína-proteína, o alinhamento múltiplo também foi realizado no software CLUSTAL (CLUSTAL, 2019) ômega (EMBL-EBI, 2019).

Após pesquisas na literatura, sobre organismos que também fossem ricos em $\beta$ caroteno, novos alinhamentos foram realizados com os genes e proteínas dos organismos em comparação direta com a cenoura, através do BLAST e CLUSTAL, obtendo as identidades entre os organismos e gerando a árvore filogenética.

\section{Resultados e Discussão}

Experimento 1: Após 60 dias (imagem1), ocorreu a medição do tamanho de 10 grânulos de cada repetição realizada em cada tratamento, a média de tamanhos encontra-se na tabela 3.

Tabela 3. Tamanho médio das plantas obtido após 60 dias Germinação da Phalaenopsis no tratamento 1 (meio Knudson), tratamento 2 (meio MS), e tratamento 3 (meio Knudson com 10\% (v/v) de suco de Cenoura). Análise estatística realizada foi teste Tukey a 95\% de significância.

\begin{tabular}{cc} 
Meio de Cultura & Tamanho médio das plantas $(\mathrm{mm})$ \\
\hline T1 - Meio Knudson & $2,63 \mathrm{ab}$ \\
T2 - Meio MS & $3,3 \mathrm{ab}$ \\
$\begin{array}{c}\text { T3 - Meio Knudson+10\% }(\mathrm{v} / \mathrm{v}) \\
\text { Suco de Cenoura }\end{array}$ & $3,95 \mathrm{ab}$ \\
\hline
\end{tabular}

Fonte: Autor (2019).

Os dados registram resultados superiores para as sementes de Phalaenopsis híbrida germinada no tratamento 3 (meio knudson suplementado com suco de cenoura), enquanto o tratamento 1 obteve os menores resultados., entretanto nenhum dos resultados obtidos foi estatisticamente significativo, levando em consideração os testes de homogeinidade e homoestaticidade. 
Imagem 1. Germinação da Phalaenopsis após 60 dias no tratamento 1 (meio Knudson), tratamento 2 (meio MS) e tratamento 3 (meio Knudson $+10 \%$ (v/v) de suco de Cenoura).

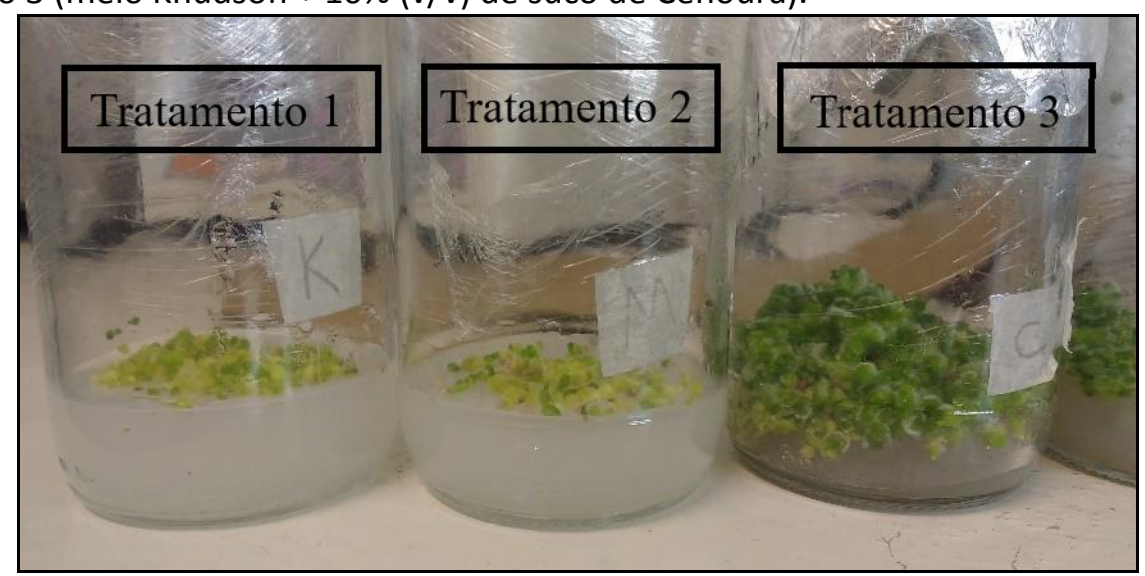

Fonte: Autor (2019).

Os resultados observados (imagem 1), asseguram que o tratamento 3 apresenta maior volume e presença de sementes germinadas. Embora, o meio padrão utilizado seja o MS (MURASHIGUE; SKOOG, 1962; SU et al., 2012) diversos trabalhos obtiveram resultados satisfatórios para a germinação de sementes de orquídeas em meios alternativos (CHUGH et al., 2009), por exemplo um meio de cultura utilizado para a germinação das sementes composto por tomate $(150 \mathrm{~mL} / 500 \mathrm{~mL}$ de suco sem sementes e casca) (KARSBURG, 2007), um meio com o fertilizante comercial NPK e adição de polpa de banana nanica $\left(60 \mathrm{gL}^{-1}\right)$, é o mais efetivo no cultivo in vitro de Dendrobium nobile Lindl (SU et al., 2012).

Os resultados obtidos nos experimentos realizados, no presente trabalho, foram similares aos resultados obtidos por Zahara (2017), onde a combinação de $10 \%(\mathrm{v} / \mathrm{v}$ ) de suco de cenoura mostrou bons resultados na maioria dos parâmetros registrados para a germinação e crescimento das plantulas da Phalaenopsis híbrida (ZAHARA et al., 2017; HSU et al., 2010).
Visando a economia na obtenção de mudas de orquídeas do gênero Phalaenopsis, os valores obtidos no site da Sigma-Aldrich (SIGMAALDRICH, 2019b) mostram que um frasco de meio de $10 \mathrm{~L}$ de cultivo MS custa $\mathrm{R} \$ 278,00$, enquanto um frasco de $10 \mathrm{~L}$ de meio Knudson custa R\$ 180,00. Logo em relação a viabilidade econômica o meio indicado é o Knudson. Caso este meio seja suplementado com suco de cenoura serão obtidos resultados superiores em comparação com os demais meios de cultivo e será mais viável economicamente, levando em consideração de que o valor para o $\mathrm{kg}$ de cenoura gira em torno de $\mathrm{R} \$ 1,00$ a 2,75 .

Experimento 2: Para o cultivo da orquídea Phalaenopsis, testando quatro tratamentos distintos, podemos observar os primeiros resultados obtidos no primeiro subcultivo, após 120 dias, na tabela 4. 
Tabela 4. Parâmetros analisados da Phalaenopsis no primeiro Subcultivo ocorrido após 120 dias da inoculação, nos quatro tratamentos estabelecidos, teste Tukey a 95\% de significância foi utilizado para análise estatística. *a são resultados significativos a $5 \%$ de variância. Tratamento 1 (MS $1 \mathrm{x}$, meio Murashige; Skoog na concentração normal), Tratamento 2 (MS 2x, meio Murashige; Skoog com o dobro da concentração), Tratamento 3 (meio Knudson com suplemento de $10 \%$ (v/v) de suco de cenoura) e Tratamento 4 (meio Knudson com reguladores de crescimento BAP/ANA nas concentrações 0,04/0,02 $\mathrm{mg}^{*} \mathrm{~L}^{-1}$ ). Quanto aos parâmetros analisados № Ca (calos); № $\mathrm{Br}$ (brotos); № Ra (raíz); APA (altura da parte aérea); CRL (comprimento da raíz mais longa); PM (peso úmido médio das plântulas); Per (perecimento); e Oxi (oxidação).

Parâmetros analisados no cultivo in vitro da Phalaenopsis

\begin{tabular}{|c|c|c|c|c|c|c|c|c|}
\hline Meio de Cultura & № Ca & № $\mathrm{Br}$ & № de Ra & APA $(\mathrm{cm})$ & $\mathrm{CRL}(\mathrm{cm})$ & PM (g) & (\%) Per & (\%) Oxi \\
\hline Tratamento 1 & $0,258 a b$ & $1,088 a b$ & $0,275 a b$ & $0,208 a b$ & $0,076 a b$ & $0,063 a b$ & 56,25 & 28,57 \\
\hline Tratamento 2 & $0,412 a b$ & $1,862 a b$ & $0,538 a b$ & $0,307 a b$ & $0,147 a b$ & $0,048 a b$ & 31,5 & 34,54 \\
\hline Tratamento 3 & $0,138 a b$ & $7,7875 * a$ & $1,338 a b$ & $0,862 a b$ & $0,922 a b$ & $0,122 a b$ & 25 & 5 \\
\hline Tratamento 4 & $0,262 a b$ & $0,775 a b$ & $0,088 a b$ & $0,058 \mathrm{ab}$ & $0,019 a b$ & $0,016 a b$ & 53,75 & 27,03 \\
\hline
\end{tabular}

Fonte: Autor (2019).

Para a primeira análise, somente 0 tratamento 3 (meio com suco de cenoura) teve resultado significativo no parâmetro número de brotos, apresentando também os menores índices de oxidação, perecimento e formação de calos, que são parâmetros indesejáveis no processo.

Um segundo subcultivo foi necessário, nesta etapa resultados significativos foram obtidos para altura da parte aérea e comprimento da raiz mais longa no tratamento 3, e somente após 180 dias o tratamento 4 (meio knudson com reguladores de crescimento) iniciou seu período de brotações, com um atraso discrepante frente aos demais tratamentos.

A última análise realizada, ocorreu aos 365 dias após a germinação das sementes, os dados constam na tabela 5, e são melhor visualizados na imagem 2 . 
Tabela 5. Parâmetros analisados da Phalaenopsis no primeiro Subcultivo ocorrido após 365 dias do primeiro subcultivo, nos quatro tratamentos estabelecidos. Teste Tukey a 95\% de significância foi utilizado para análise estatística. *a são resultados significativos a 5\% de variância. Tratamento 1 (MS 1x, meio Murashige; Skoog na concentração normal), Tratamento 2 (MS 2x, meio Murashige; Skoog com o dobro da concentração), Tratamento 3 (meio Knudson com suplemento de $10 \%$ (v/v) de suco de cenoura) e Tratamento 4 (meio Knudson com reguladores de crescimento BAP/ANA nas concentrações 0,04/0,02 $\mathrm{mg}^{*} \mathrm{~L}^{-1}$ ). Quanto aos parâmetros analisados № Ca (calos); № $\mathrm{Br}$ (brotos); № Ra (raíz); APA (altura da parte aérea); CRL (comprimento da raíz mais longa); PM (peso úmido médio das plântulas); Per (perecimento); e Oxi (oxidação).

\section{Parâmetros analisados no cultivo in vitro da Phalaenopsis}

\begin{tabular}{|c|c|c|c|c|c|c|c|c|}
\hline Meio de Cultura & № Ca & $\mathrm{N} N \mathrm{Br}$ & № de Ra & APA $(\mathrm{cm})$ & $\mathrm{CRL}(\mathrm{cm})$ & PM (g) & (\%) Per & (\%) Oxi \\
\hline Tratamento 1 & $0,18 a b$ & $1,22 a b$ & $0,6668 a b$ & $1,34 a b$ & $0,73 a b$ & $1,2 a b$ & 26 & 13,5135 \\
\hline Tratamento 2 & $0,72 a b$ & $1,6 a b$ & $0,638 a b$ & $0,94 a b$ & $0,7816 a b$ & $0,805 a b$ & 32 & 52,9412 \\
\hline Tratamento 3 & $0 a b$ & $1,14 a b$ & $2,616 * a$ & $6,32 * a$ & $3,606 * a$ & $4,3417 * a$ & 0 & 0 \\
\hline
\end{tabular}

Fonte: Autor (2019).

O tratamento 3 (meio com suco de cenoura) obteve resultados significativos nos parâmetros: peso médio úmido das plantas, comprimento da raiz mais longa, altura da parte aérea e no número de raízes por planta. Além de não haver indícios de oxidação e percas de plantas, enquanto os demais tratamentos possuem oxidação e contaminação constantes (imagem 3).
Imagem 2. Phalaenopsis após 365 dias da inoculação das sementes, nos quatro tratamentos identificados na imagem, Tratamento 1 (MS 1x, meio Murashige e Skoog na concentração normal), Tratamento 2 (MS 2x, meio Murashige e Skoog com o dobro da concentração), Tratamento 3 (meio Knudson com suplemento de $10 \%$ (v/v) de suco de cenoura) e Tratamento 4 (meio Knudson com reguladores de crescimento BAP/ANA nas concentrações $\left.0,04 / 0,02 \mathrm{mg}^{*} \mathrm{~L}^{-1}\right)$.

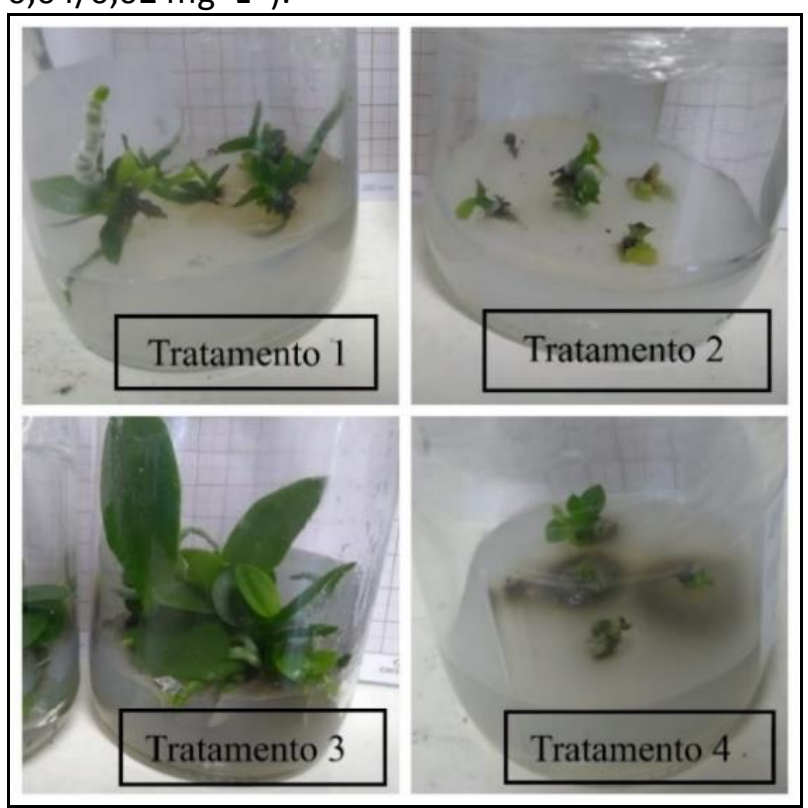

Fonte: Autor (2019). 
Tais resultados revelam que o melhor tratamento é o meio Knudson suplementado com $10 \%(\mathrm{v} / \mathrm{v})$ de suco de cenoura (tratamento 3 ), para o cultivo de orquídeas do gênero $P$. híbrida de acordo com os resultados estatísticos obtidos e pela observação das imagens registradas após 365 dias de cultivo.

Analisando os resultados da tabela 3,0 tratamento 1 (Knudson puro) foi o menos eficaz para germinação das sementes. Segundo dados literários o meio MS é o mais empregado para o cultivo de orquídeas (SOUZA et al., 2000), entretanto o meio suplementado com suco de cenoura, um aditivo orgânico indeterminado, demonstrou os melhores resultados para o cultivo in vitro de Phalaenopsis.

O meio de cultura suplementado com suco de cenoura demonstrou, no decorrer das análises, os menores índices de oxidação, perecimento de plantas e formação de calos. Enquanto o tratamento que continha reguladores de crescimento e o meio MS demonstraram altos índices de oxidação e perecimento. A oxidação é causada por reações de polifenoxidases acima de compostos fenólico (SOUZA et al., 2000), sendo indesejável no cultivo in vitro, pois, compromete a qualidade das plantas e pode provocar limitações nas respostas morfogênicas em culturas de tecidos limitando o desempenho na multiplicação celular (JORDAN et al., 1998).

Para os tratamentos 1 (MS 1x), 2 (MS 2x) e 4 (Knudson + reguladores de crescimento), do segundo experimento, os subcultivo deveriam ser realizados em períodos de tempos menores, visto a saturação do meio de cultivo, porém tal ato elevaria os custos com a produção de meios de cultura e as chances de contaminações são acrescidas.

As taxas de perecimento mais elevadas foram obtidas no tratamento 4 , meio knudson com reguladores de crescimento, pois o uso em excesso de reguladores nas quantidades estabelecidas para o segundo experimento tornou-se tóxica para as plantas. Foi o tratamento que obteve $100 \%$ de oxidação, fato justificado pela eficiência dos reguladores de crescimento depender e ser influenciada pelo conteúdo endógeno que essas substâncias podem causar em contato com o tecido do explante (GRATTAPAGLIA; MACHADO, 1998).

$O$ desempenho para a germinação e o crescimento da Phalaenopsis no tratamento 3 (meio Knudson suplementado com suco de cenoura) em ambos os experimentos, foi superior aos demais tratamentos obtendo-se resultados significativos para os parâmetros de número de raízes, comprimento da raiz mais longa, altura da parte aérea e peso úmido.

Experimento 3: A cenoura é rica em $\beta$-caroteno, através de buscas realizadas no NCBI pela Daucus carota, foi acessado pelo ID: 108224246, popularmente conhecida como cenoura. A última atualização efetuada no NCBI sobre o gene foi em 08 de abril de 2017. O gene descrito foi o $\beta$ caroteno 3-hidroxilase (BCH-1), localizado no cromossomo 6 com ORF Names:DCAR_020269, as informações disponíveis no UniProt, que teve última atualização em 10 de abril de 2019, conincidem com os obtidos no NCBI.

O $\beta$-carotene hydroxylase é um componente integral da membrana, os domínios e repetições dessa proteína se encontram na região 149-276 de uma sequência de 309 aminoácidos (EMBL-EBI, 2019).

No UniProt se encontram informaçãoes quanto a funcionalidade molecular, como a de ligação íon de ferro através de acesso GO:00006 GONUTS, a interação é seletiva e não ocorre com íons de ferro covalente, obtevese 1.069.172 anotações. Quanto a atividade oxirredutase, de acesso GO:0016491 GONUTS, contém informações sobre a catálise da reação de oxirredução, uma reação reversível, na qual se alteram o estado oxidativo dos átomos. O processo biosintético lipídico, acesso GO:0008610 GONUTS, possui 3.510 .189 anotações e referese as reações químicas e vias que formam os lipídeos (UNIPROT, 2019).

Através do alinhamento por BLASTX, verificou-se com alinhamento de nucleotídeo traduzido e proteína o organismo que possui gene similar, com Query cover: $28 \%$ encontra-se a Vitis vinifera (Ident:55\%), uma variedade de uva.

Um alinhamento através da proteína do $\beta$-caroteno da Cenoura: beta-carotene 3hydroxylase, em PROTEIN BLAST, na busca do alinhamento da proteína desejada, com proteínas de demais organismo encontrou-se: Com Query cover de $97 \%$, a V. vinifera (Ident $72 \%$ ), que já havia demonstrado similaridade na busca anterior. O mesmo organismo foi encontrado com a mesma similaridade quando o alinhamento foi realizado no UniProt.

Alguns organismos que também são ricos em $\beta$-caroteno são a laranja, melão, abóbora, moranga, pepino, espinafre e couve (RODRIGUEZ-AMAYA et al., 2008), seus genes e 
proteínas foram acessados em bancos de dados, UniProt, e alinhados em comparação com o $\beta$ - caroteno da cenoura, obtendo os seguintes resultados (tabela 6).

Tabela 6. Alinhamentos especificos, de organismos ricos em $\beta$-caroteno, de gene e proteína comparados com o gene e proteína do $\beta$-caroteno da cenoura (Daucus carota) nos programas BLAST e CLUSTAL.

\section{Organismos Alinhados com o $\beta$-carotene 3-hydroxylase da Daucus carota}

BLAST \%

Gene

Nenhuma semelhança significativa encontrada

Nenhuma semelhança significativa encontrada

Query Cover: 2 Ident: 85.37

Nenhuma semelhança significativa encontrada

Nenhuma semelhança

Cucúrbita máxima (Moranga)

Brassica oleracea (Couve/brocolis)

Cucumis sativus (Pepino)

Fonte: Autor (2019).

O CLUSTAL apresentou resultados mais precisos que o BLAST para o presente trabalho pois, o BLAST realiza somentes alinhamentos locais, enquanto o CLUSTAL realiza alinhamentos múltiplos (SANTOS, 2004). Através dos alinhamentos observamos que os valores de cobertura abaixo de $40 \%$ não representam um bom resultado, pois, não podemos afirmar que está nesta região o domínio da proteína que foi encontrado como similar. Sugere-se análises complementares para verificação da real similaridade entre os organismos analisados.

Entretanto podemos verificar que o gene e a proteína do $\beta$-caroteno da abóbora demonstram parcial similaridade tanto no BLAST quanto no CLUSTAL, levantando a possibilidade

CLUSTAL \%

Proteína

Não há proteína sequenciada

Query Cover: 40 Ident: 89.52

Query Cover: 98 Ident: 70.57

Não há proteína sequenciada

Não há proteína sequenciada

Não há proteína sequenciada
Ident: 36.41

\section{Proteína}

Não há proteína

Ident: 41.10 sequenciada

Ident: 38.96

Ident: 86.96

Ident: 73.63

Ident: 42.43

Ident: 39.36

Não há proteína sequenciada

Ident:

43.11

Não há proteína sequenciada

Não há proteína sequenciada para que futuros trabalhos analisem tais resultados.

Analisando somente os dados originados no CLUSTAL, o gene com a maior porcentagem apresentada foi o da moranga,ainda sendo inferior a $40 \%$ o que não garante a real similaridade referente ao gene, a sequencia da proteína ainda não foi depositada no banco de dados, para obter informações mais concretas. Em realação as proteínas alinhadas a mais significativa foi o $\beta$-caroteno da laranja.

Os cladogramas obtidas no CLUSTAL permitem visualizar a proximidade dos organismos como é possível verificar (figura 4 e $5)$. 
Figura 4. Genes do $\beta$-caroteno, dos organismos listados na tabela 6 , alinhados com o gene do $\beta$-caroteno da Daucus carota (NC_030386.1). Os organismos listados correspondem a NC_027756 (Brassica oleracea couve); NW_018931396 (Spinacia oleracea - espinafre); NC_03038.1 (Daucus carota - Cenoura); NC_023050 (Citrus sinensis - Laranja); NC_026659 (Cucumis sativus - pepino); NW_019104490 (Momordica charantia - melão); NW_019268566 (Cucurbita moschata - abóbora); NW_019272054 (Cucurbita máxima Moranga).

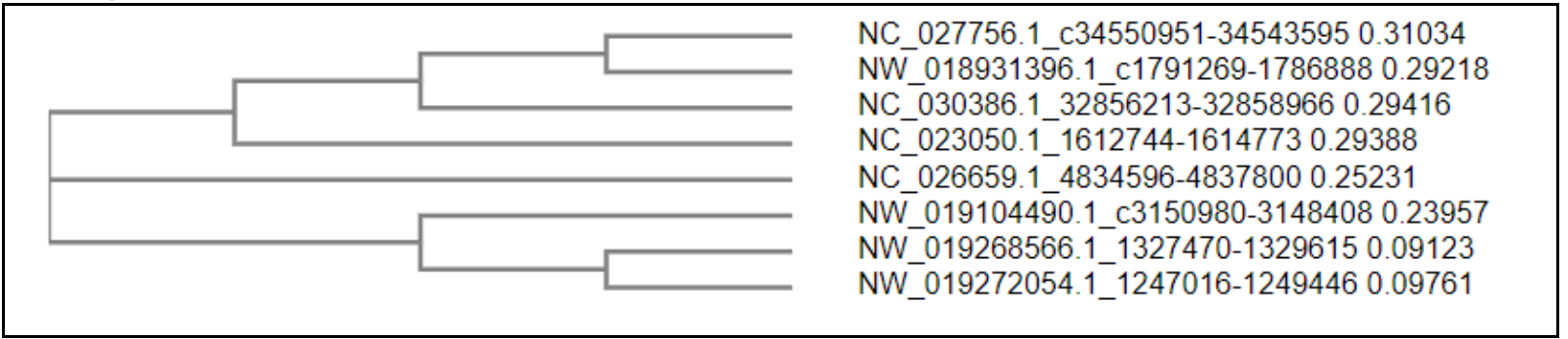

Fonte: Autor (2019).

Figura 5. Proteínas do $\beta$-caroteno, dos organismos listados na tabela 6 , alinhados com a proteína do $\beta$ caroteno da Daucus carota (DAUCS). Os organismos listados correspondem a CUCSA (Cucumis sativus Pepino); DAUCS (Daucus carota - Cenoura); CITSI (Citrus sinensis - Laranja), CUCMO (Cucurbita moschata Abóbora).

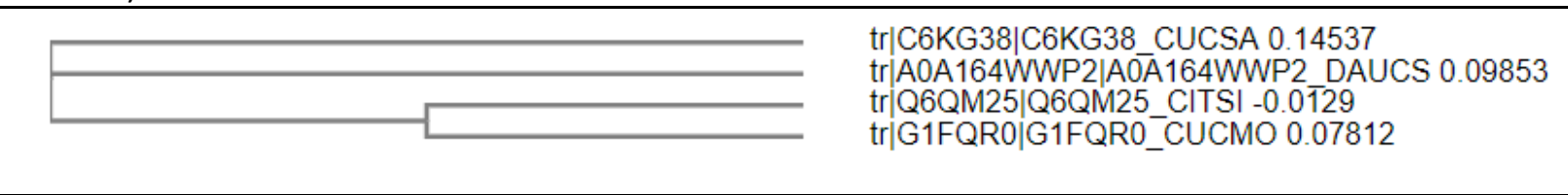

Fonte: Autor (2019).

No cladograma dos genes (figura 4), o mais similar com o gene da cenoura foi a laranja (NC_023050) na parte inferior. No cladograma das proteínas (figura 5) a laranja (CITSI) também ficou mais próxima da cenoura.

Nesse projeto é levantada a hipótese de que, possivelmente, o responsável pelos resultados superiores obtidos com o suco de cenoura, é o $\beta$-caroteno, um composto majoritário da cenoura, precursor da vitamina $A$ que exerce papel fundamental no crescimento, proliferação celular, diferenciação celular e reprodução (WEIL, 2000), pois, o principal processo para o desenvolvimento de plantas é a fotossíntese, que depende dos pigmentos da planta.

Nas plantas os carotenoides atuam na fotossíntese, como facilitadores da captação de energia e na proteção contra a foto-oxidação (KRINSKY, 1994; NAVES, 1998). Conforme citado por Silva (2013) os pigmentos que são disponibilizados em plantas são a clorofila a e b, o $\beta$-caroteno apresenta a coloração laranja e os precursores fotossintéticos são localizados nos cloroplastos (STREIT et al., 2005).

A fotossíntese compõe o metabolismo primário das plantas, dando origem a ácidos carboxílicos, aminoácidos, proteínas e outros que são vitais para as plantas (SCHAAF et al., 1995). O metabolismo primário é praticamente idêntico em todas as plantas (SANTOS, 2001), com processos químicos como a glicólise, ciclo do ácido cítrico, transaminações, síntese de proteínas, enzimas e coenzimas, reprodução celular, absorção de nutriente e afins. As clorofilas são compostas do metabolismo primário de plantas (GROENIGEN et al., 2015).

Os metabolitos secundários atuam na defesa e proteção da planta contra danos ecológicos (SAMUNI-BLANK et al., 2012) conforme a planta necessite especificamente, atuam na proteção contra predadores e auxiliam na interação com outras plantas (SAVITHRAMMA et al., 2011). Esse fator justifica a baixa incidência de oxidação e contaminação da Phalaenopsis cultivada no meio suplementado com suco de cenoura.

Por similaridade, levando em consideração o $\beta$-caroteno, um organismo que pode substituir a cenoura na suplementação de meios de cultivos é a $V$. Vinifera que obteve Query cover de $97 \%$ e um Ident de $72 \%$, entretanto a uva contém baixa concentração de carotenoides, mas a pigmentação da uva também 
é de cloroplasto (RODRIGUES-AMAYA et al., 2008).

A $V$. vinifera, por ser uma fruta ácida ao ser utilizada no preparo de meios de cultivo auxiliara no controle da oxidação, uma vez que substâncias antioxidantes são empregadas para reduzir probelmas de oxidação in vitro, exemplos de substâncias antioxidantes utilizadas são o ácido ascórbico e o ácido cítrico, esse ácido age como agente quelante, ou seja, remove íons de metal inibindo a ativação de enzimas oxidativas (PASQUAL et al., 1997).

O $\beta$-caroteno é obtido em frutas e vegetais de cor amarelo-alaranjada (abóbora, moranga, cenoura) e em vegetais de cor verdeescura (couve, espinafre, pepino) (MANGELS et al., 1993; RODRIGUEZ-AMAYA, 1997). Com o alinhamento específico, entre os organismos que são ricos em $\beta$-caroteno, o mais indicado para substituir a cenoura é a laranja, que também é rica em vitamina $\mathrm{C}$ e possui ácido cítrico, elevando a proteção contra oxidação (PASQUAL et al., 1997). Ácido cítrico já foi utilizado para reduzir a oxidação in vitro de banana 'maçã', e o trabalho obteve resultados positivos quanto a redução deste fator limitante (CAMELOSI et al., 2007).

Para comprovar se as informações, obtidas por análises bioinformáticas, estão corretas é necessário realizar um teste de comparação entre o meio de cultura suplementado com suco de cenoura e o meio de cultura suplementado com suco de laranja. Para este teste, em ambos os meios a fonte e idade de explantes de $P$. híbrida devem ser as mesmas, assim como os demais parâmetros de cultivo, de como que a única variável seja o aditivo indeterminado. Trabalhos futuros serão realizados para afirmar ou negar essa hipótese.

\section{Conclusão}

Com os resultados obtidos concluímos que o tratamento 3 (meio de cultura Knudson suplementado com $10 \%(\mathrm{v} / \mathrm{v})$ de suco de cenoura) demonstrou os melhores resultados para germinação e cultivo da Phalaenopsis, possibilitando a obtenção de mudas em tempo reduzido para 365 dias, sendo também o tratamento que demonstrou a melhor viabilidade econômica, em comparação aos demais tratamentos. A laranja (Citrus sinensis) é um possível substituto da cenoura na elaboração de meios de cultivo para orquídeas do gênero
Phalaenopsis, segundo as buscas e análises com ferramentas de bioinformática.

\section{Referências}

ALVES, S. M. A bioinformática e sua importância para a biologia molecular. Revista Brasileira de Educação e Saúde, v.3, n.4, p.18-25, 2013.

AMARAL, A. M. et al. O Programa BLAST: guia prático de utilização. EMBRAPA. Brasília, 2007. Documentos, 224.

BARROS, F. et al. Checklist of the Orchidaceae from the state of Mato Grosso do Sul, Brazil. Iheringia - Série Botânica, v.73, p.287-296, 2018. https://doi.org/10.21826/2446-8231201873s287

CAMELOSI, M. R. et al. Redução da oxidação na propagação in vitro da bananeira maçã. Ciência e Agrotecnologia, Lavras, v. 31, n. 4, p. 1237-1241, $2007 . \quad$ https://doi.org/10.1590/S1413$\underline{70542007000400044}$

COSTA, M. A. P. C. et. al. Micropropagação de orquídea. In: JUNGHANS, T. G.; SOUZA, A. da S. (Ed.). Aspectos Práticos da Micropropagação de Plantas. 2. ed. Brasília: Embrapa, 2013. p.373392.

CHUGH, S.; GUHA, S.; RAO, U. Micropropagation of orchid: a review on the potential of different explants. Scientia Horticulture, v.122, n.4, p.507520, 2009. https://doi.org/10.1016/j.scienta.2009.07.016

CLUSTAL. Clustal Omega. 2019. Disponível em: https://www.ebi.ac.uk/Tools/msa/clustalo/. Acesso em: 20 nov. 2019.

EMBL-EBI. InterPro - Protein sequence analysis \& classification. 2019. Disponível em: http://www.ebi.ac.uk/interpro/sequencesearch/i prscan5-S20190422-190214-0689-28017487p2m. Acesso em: 22 abr. 2019.

FOGAÇA, C. M. et al. Microtuberização in vitro de cultivares de mandioca: aspectos morfológicos e anatômicos. Acta Botânica Brasileira, São Paulo. v. 24 , n. 3, 2010. https://doi.org/10.1590/S0102$\underline{33062010000300004}$

GNASEKARAN, P. et al. A study on the use of organic additives on the protocorm-like bodies 
(PLBs) growth of Phalaenopsis violaceae orchid. Journal of Phytological, v. 2, p. 29-33, 2010.

GRATTAPAGLIA, D.; MACHADO, M.A. Micropropagação. In: TORRES, A.C.; CALDAS, L.S.; BUSO, J.A. Cultura de tecidos e transformação genética de plantas. 2. ed. Brasília: EMBRAPASPI; EMBRAPA-CNPH, 1998. v.1, p.183-260.

GROENIGEN, J. W. et al. The soil N cycle: new insights and key challenges. Soil, v. 1, p. 235-256, 2015. https://doi.org/10.5194/soil-1-235-2015

HOFFMANN, A. M. et al. Cultura de tecidos: aplicações na propagação de plantas. Universidade Federal de Lavras, p. 130, 1997.

HSU, S.; CHUANG, H.-T.; SHEN, T.-M. Breeding Barriers in Red Phalaenopsis Orchids. Acta Horticulturae, v.878, n.29, p.145-152, 2010. https://doi.org/10.17660/ActaHortic.2010.878.16

JORDAN, M.I.; ROVERANO, L.; GOUREUX, A. Promotion of Annona cherimoya in vitro shoot morphogenesis as influenced by antioxidants. Gartenbauwissenschaft, Stuttgart, v. 56, n. 5, p. 224-227, 1998.

JORGE, J.; JURAS, M. C. R.; SUZUKI, R. M. Germinação e Crescimento inicial in vitro de Cattleya warneri T. Moore (Orchidaceae). Revista Brasileira de Biociências, Porto Alegre, v.13, n.3, p.134-141, 2015.

KARSBURG, I. V. Germinação de sementes de Dendrobium phalaenopsis em meio de cultura alternativo. In: CONGRESSO BRASILEIRO DE FLORICULTURA E PLANTAS ORNAMENTAIS, 16. Goiânia. Anais [...]. 2007.

KNUDSON, L. A new nutrient solution for the germination of orchid seed. American Orchid Society Bulletin, v. 14, n. 2, p.214- 217, 1946.

KRINSKY, N. I. The biological properties of carotenoids. Pure \& Applied Chemistry, v. 66, n.5, p.1003-1010, 1994. https://doi.org/10.1351/pac199466051003

LOPES, F. M. A Bioinformática Aplicada no Melhoramento de Plantas. In: Encontro Paranaense de Melhoramento de Plantas, 2. Anais [...]. 2012. p. 1-5.
MANGELS, A.R. et al. Carotenoid content of fruits and vegetables: an evaluation of analytic data. Journal of the American Dietetic Association, Chicago, v.93, n.3, p.284-296, 1993. https://doi.org/10.1016/0002-8223(93)91553-3

MINAMIGUCHI, J. Y.; MACHADO NETO, N. B. Embriogênese Somática Direta Em Folhas De Phalaenopsis: Orchidacease. Colloquium Agrariae, v.3, n.1, p.07-13, 2007. https://doi.org/10.5747/ca.2007.v03.n1.a22

MIYATA, L. Y.; VILLA, F.; PASQUAL, M. Meios de cultura utilizados na micropropagação de híbridos de orquídeas. Semina: Ciências Agrárias, Londrina, v.35, n.4, p.1731-1738, 2014. https://doi.org/10.5433/1679-

$\underline{0359.2014 v 35 n 4 p 1731}$

MURASHIGE T; SKOOG F. A revised medium for rapid growth and bioassays with tobacco tissue cultures. Physiologia Plantarum, v.15, p.473-497, $1962 . \quad$ https://doi.org/10.1111/j.13993054.1962.tb08052.x

MURDAD, R. et al. Effects of carbon source and potato homogenates on in vitro growth and development of Sabah's endangered orchid: Phalaenopsis gigantea. Asia-Pacific Journal of Molecular Biology and Biotechnology, v. 18, p. 199-202, 2010.

NAVES, M. M. V. Beta - Caroteno E Câncer. Revista de Nutrição, v.11, n.2, p.99-115. Campinas, 1998. https://doi.org/10.1590/S1415$\underline{52731998000200001}$

PASQUAL, M.; HOFFMANN, A.; RAMOS, J.D. Cultura de tecidos vegetais: tecnologia e aplicação. Lavras: UFLA, 1997. p. 159.

PROSDOCIMI, F.; SANTOS, F. S. Sobre bioinformática, genoma e ciência. Ciência Hoje, v. 35, n. 209, p. 54-57, 2004.

RODRIGUEZ-AMAYA, D. B. Carotenoids and food preparation: the retention of provitamin a carotenoids in prepared, processed, and stored foods. Arlington: John Snow, 1997.

RODRIGUEZ-AMAYA, D. B.; KIMURA, M.; AMAYAFARFAN, J. Fontes brasileiras de carotenoides: tabela brasileira de composição de carotenoides em alimentos. Brasília: MMA/SBF, p. 100, 2008. 
ROYAL FLORA HOLLAND. Annual report 2018: Top 5 Kamerplanten. 2018. Disponível em: http://annualreport.royalfloraholland.com/?_ga= 2.32929982.1210685090.153704586-

565804113.1537704586\#/feiten-en-

cijfers/kamerplanten?_k=i558by. Acesso em: 22 abr. 2019.

SANTOS, R. I. Metabolismo básico e origem dos metabólitos secundários. In: SIMÕES, C. M. O. et al. Farmacognosia: da planta ao medicamento. 3. ed. Porto Alegre/Florianópilis: Ed.Universidade/UFRGS/Ed.UFSC, 2001.

SANTOS, E. C. Uma introdução à Bioinformática através da análise de algumas ferramentas de software livre ou de código aberto utilizadas para o estudo de alinhamento de sequências. 2004. 88f. Monografia (Especialização) Administração em Redes Linux, Universidade Federal de Lavras, 2004.

SAMUNI-BLANK, M. et al. Intraspecific directed deterrence by the mustard oil bomb in a desert plant. Current Biology, v. 13, n. 22, p. 1218-1220, 2012. https://doi.org/10.1016/j.cub.2012.04.051

SAVITHRAMMA, N. et al. Screening of medicinal plants for secondary metabolites. Middle-East Journal of Scientific Research, n.8, p.579-584, 2011.

SIGMA-ALDRICH. Murashige and Skoog Basal Medium. 2019a. Disponível em: https://www.sigmaaldrich.com/catalog/search?t erm=meio+murashige+e+skoog\&interface $=$ All \&N $=0 \&$ mode $=$ match\%20partialmax\&lang=pt\&regio n=BR\&focus=product. Acesso em: 12 dez. 2019.

$\begin{array}{lllr}\text { SIGMA-ALDRICH. Knudson } & \text { C Modified } & \text { Orchid } \\ \text { Medium. } & 2019 \mathrm{~b} . & \text { Disponível } & \text { em: }\end{array}$ https://www.sigmaaldrich.com/catalog/product/ sigma/k4003 lang $=$ pt\& region $=B R \& g c l i d=C j w K C A j$ w7MzkBRAGEiwAkOXexE3k2Md9WYDcxd67mXkZ hI2xBVL_yMMQkhg9SXV2EqueQsfcv07qJhoCPnM QAvD_BwE. Acesso em: 12 dez. 2019.

SILVA, A. R. et al. Extração de pigmentos fotossintéticos em folhas das espécies de café (coffea arábica), acálifa (acalypha hispida) e urucum (bixa orellana) por meio de cromatografia em papel. In: SIMPÓSIO DE PESQUISA DOS CAFÉS DO BRASIL, 8. Anais [...]. Salvador, 2013.
SOUZA, A. S.; CORDEIRO, Z. J. M.; TRINDADE, A. V. Produção de mudas. In: CORDEIRO, Z. J. M. Banana: produção. Brasília: Embrapa Comunicação para Transferência de Tecnologia, 2000. p. 39-46.

SU, M. J.; SCHNITZER, J. A.; FARIA, R. T. Polpa de banana e fertilizantes comerciais no cultivo in vitro de orquídea. Científica, Jaboticabal, v.40, n.1, p.28-34, 2012.

SCHAAF, J. et al. Primary metabolism in plant defense. Plant Physiol., n. 108, p. 949-960, 1995. https://doi.org/10.1104/pp.108.3.949

SCHOENMAKER, K. Boletim Informativo Ibraflor. v. 81, 2017.

STREIT, M. N. et al. As Clorofilas. Ciência Rural, v.3, n.35, p.748-755, 2005. https://doi.org/10.1590/S0103-

$\underline{84782005000300043}$

TOMBOLATO, A. F. C.; COSTA, A. M. M. Micropropagação de plantas ornamentais. Campinas: Instituto Agronômico, 1998. p.72. (Boletim técnico, 174)

UNIPROT. UniProtKB-A0A164WWP2-Daucus. $2019 . \quad$ Disponível em: https://www.uniprot.org/uniprot/A0A164WWP2. Acesso em: 22 abr. 2019.

WEIL, J. H. Bioquímica geral. 2. ed. Lisboa: Fundação Calouste Gulbenkian, 2000. p.316.

ZAHARA, M. et al. The effects of different media, sucrose concentrations and natural additives on plantlet growth of Phalaenopsis hybrid "pink". Brazilian Archives of Biology and Technology, v.60, Dec. p.1-15, 2017. https://doi.org/10.1590/1678-4324-2017160149

ZAHARA, M.; DATTA, A.; BOONKORKAEW, P. Effects of sucrose, carrot juice and culture media on growth and net $\mathrm{CO}_{2}$ exchange rate in Phalaenopsis hybrid 'Pink'. Scientia Horticulturae, v.205, p.17-24, 2016. https://doi.org/10.1016/j.scienta.2016.04.011 